\title{
Respiratory syncytial virus in the Western Pacific Region: a systematic review and meta-analysis
}

\author{
Krisna N A Pangesti ${ }^{1,2,3}$, \\ Moataz Abd El Ghany,2,4, \\ Alison M Kesson ${ }^{4,6,7}$, \\ Grant A Hill-Cawthorne ${ }^{1,4}$ \\ ${ }^{1}$ School of Public Health, Faculty of \\ Medicine and Health, The University of \\ Sydney, Australia \\ ${ }^{2}$ The Westmead Institute for Medical \\ Research, The University of Sydney, \\ Sydney, Australia \\ ${ }^{3}$ Center for Research and Development \\ of Biomedical and Basic Health \\ Technology, NIHRD, Jakarta, Indonesia \\ ${ }^{4}$ Marie Bashir Institute of Infectious \\ Diseases and Biosecurity, The University \\ of Sydney, Sydney, Australia \\ ${ }^{5}$ The Westmead Clinical School, Faculty \\ of Medicine and Health, The University \\ of Sydney, Sydney, Australia \\ ${ }^{6}$ Discipline of Child and Adolescent \\ Health, The University of Sydney, \\ Sydney, Australia \\ ${ }^{7}$ The Children Hospital at Westmead, \\ Department of Infectious Diseases and \\ Microbiology, Sydney, Australia
}

\begin{abstract}
Background Respiratory syncytial virus (RSV) is the leading cause of viral pneumonia and bronchiolitis, especially in younger children. The burden of RSV infection in adults, particularly in the older age group, is increasingly recognised. However, RSV disease burden and molecular epidemiology in the World Health Organization (WHO) Western Pacific Region (WPR) has not been reviewed systematically. The aim of this systematic review is to investigate the epidemiological aspects of RSV (incidence, prevalence, seasonality and hospitalisation status) and the associated molecular data in the WPRO countries.
\end{abstract}

Methods A systematic search was conducted in international literature databases (MEDLINE, EMBASE, Scopus and Web of Science) to identify RSV-related publications from January 2000 to October 2017 in the WPR countries.

Results A total of 196 studies from 15 WPR countries were included. The positivity rate for RSV among respiratory tract infection patients was $16.73 \%$ (95\% confidence interval $(\mathrm{CI})=15.12 \%-18.4 \%$ ). The RSV-positive cases were mostly found in hospitalised compared with outpatients (18.28\% vs $11.54 \%, P<0.001$ ), and children compared with adults (20.72\% vs $1.87 \%, P<0.001$ ). The seasonality of RSV in the WPR countries follows the latitude, with the peak of RSV season occurring in the winter in temperate countries, and during the rainy season in tropical countries. The molecular epidemiology pattern of RSV in WPR countries was similar to the global pattern, with NA1 (RSV A) and BA (RSV B) being the predominant genotypes.

Conclusions The available data on RSV are limited in several countries within the WPR, with most data focusing on children and hospitalised patients. Further studies and surveillance, incorporating laboratory testing, are needed to determine the burden of RSV infection in the WPR countries.

\section{Correspondence to:}

Krisna N A Pangesti, MD, MS

The University of Sydney

Edward Ford Building, A27 Fisher Rd

School of Public Health

Faculty of Medicine and Health

Sydney NSW 2006

Australia

kpan4827@uni.sydney.edu.au
Respiratory syncytial virus (RSV) is the leading cause of viral pneumonia and bronchiolitis, especially in younger children. The global estimate of RSV cases in children in 2015 was 33.1 million, with 3.2 million of these requiring hospitalisation [1]. The global estimated age-specific death rates due to RSV pneumonia in 2010 was 3.5 per 100000 population, with RSV contributing $6.7 \%$ and $1.6 \%$ of all deaths in the 28-364 day-old and in the 1-4 year-old age groups, respectively [2]. Although most RSV studies to date have focused on children, the burden of RSV infection in adults, particularly in the older age group, is increasingly recognised [3-6]. Both asymptomatic and mild in- 
fection in adults raises the possibility that they may act as a source of paediatric infections that could be reduced through future vaccination [7].

Recently, RSV has been receiving more attention as one of the major viral respiratory pathogens causing acute lower respiratory infections in younger children. RSV epidemiological data, including incidence and prevalence, were estimated from different sources, including scientific publications and hospital reports. These data are usually limited to a specific location, community or hospital, during a specific time period, and therefore it is often difficult to conclude prevalence figures or estimate their accuracy. Several systematic reviews have tried to determine the burden of RSV infection, especially in children, in different regions in the world [1,8-10]. RSV epidemiological data are required to properly plan resource allocation and public health policies for disease control, particularly when or if a vaccine becomes available. In the future, surveillance that incorporates laboratory diagnostic testing using molecular techniques should provide information about transmission, evolution and the emergence of new RSV genotypes and strains that will help in establishing preventive measures to control RSV infection. The World Health Organization (WHO) has started piloting RSV surveillance in 14 countries since mid-2017 with the objective to obtain evidence-based data which will help in developing RSV vaccination policy [11].

The WHO Western Pacific Region (WPR), which consists of 37 countries in Asia, Oceania and the Pacific, is very diverse regarding demographics, political and socio-economic status, and includes health care systems that vary in terms of funding and resilience. The population of the WHO WPR area is approximately 1.9 billion people, which is approximately $25 \%$ of the global population [12]. There are an estimated 0.11 pneumonia episodes per child-year, with 61900 pneumonia-related deaths annually in the WPR area [13]. The contribution of viral pathogens in acute lower respiratory tract infections in the region has, to date, mostly been provided by influenza data, as surveillance for Influenza is already conducted in 15 WPR countries [14]. However, the burden of RSV infections in the WPR region, in both adults and children is still unclear.

We reviewed RSV studies conducted in the WPR countries from January 2000 to October 2017 to investigate the epidemiological aspects of RSV: (incidence), prevalence, seasonality and hospitalisation status, and the associated molecular epidemiology data. To the best of our knowledge, this is the first review to systematically analyse RSV-related epidemiological data in the WPR countries.

\section{METHODS}

\section{Search strategy}

Searches were systematically carried out in the main international literature databases (MEDLINE, EMBASE,Web of Science and SCOPUS), using the search terms: "RSV" OR "respiratory syncytial virus" AND "prevalence" OR "positivity" OR "rate" OR "infection" OR "proportion" OR "frequency" in combination with each WPR country $(\mathrm{n}=37)$ using the Preferred Reporting Items for Systematic Reviews and Meta-analysis (PRISMA) guidelines [15]. The date of the search was $30^{\text {th }}$ October 2017. The final reference list of the articles included was reviewed for additional information. We also searched the web pages of all countries' Ministries of Health and the WHO and WPR Office websites.

\section{Selection criteria}

Studies were included if the following criteria were fulfilled: 1) studies in humans; 2) studies in patients with acute respiratory tract infection (ARTI) or lower respiratory tract infection (LRTI) or influenza-like illness (ILI); 3) studies that reported one or more of the following: incidence, prevalence, seasonality, or molecular epidemiology (genotypes); and 4) studies published in English. Studies published or reported between January 2000 and October 2017 were included. We excluded articles if they were: 1) basic science or animal studies, 2) replication of studies, 3) nosocomial cases of RSV, or 4) case reports.

\section{Data extraction and analysis}

Literature screening was performed by assessing title, keyword and abstract. EndNote X7.5 (Thomson Reuters) was used for bibliography management, in which duplicates were removed before the initial screening. The first screening after removing 1027 duplicates was performed by excluding the irrelevant abstracts. Full-text screening was then conducted on 370 articles and a total of 196 papers were eligible for the study. The following data from eligible studies were extracted: study location (city, country); years 
and duration; setting (inpatient, outpatient); participant age; number of individuals and/or respiratory samples tested; number of RSV-positive specimens; number of each type of RSV-positive specimens (RSV $\mathrm{A}$ and RSV B); and number of genotypes identified.

We conducted meta-analyses using the Der-Simonian and Laird method using random-effects models [16] to calculate the pool of the RSV proportions by country, inpatient/outpatient, age, and RSV detection methods. The random-effects model was used because we assumed that the true estimates vary from study to study. All analyses were performed using MedCalc software version 19.05 (MedCalc Software, Belgium).

\section{Primary and secondary outcomes}

This systematic review included the following outcomes: (i) incidence and prevalence of RSV infections, (ii) percentage of ILIs and LRTIs being caused by RSV by demographic (age, country) and hospitalisation status (inpatients vs outpatients), and (iii) seasonality and molecular epidemiology.

\section{RESULTS}

We identified 2072 articles, from which 196 studies were included based on our eligibility criteria (Figure 1), with two studies covering three WPR countries [18,19]. These included studies were only from 15 of the 37 countries listed in the WHO WPR. The map of WHO WPR countries and the distribution of the included RSV studies are shown in Figure 2. Of the 196 studies, 193 studies reported RSV-positivity rate, 13 studies reported the incidence, 95 studies reported seasonality and 43 studies reported RSV sub-grouping. The detailed information about the articles included in this study is provided in Table S1 in the Online Supplementary Document.

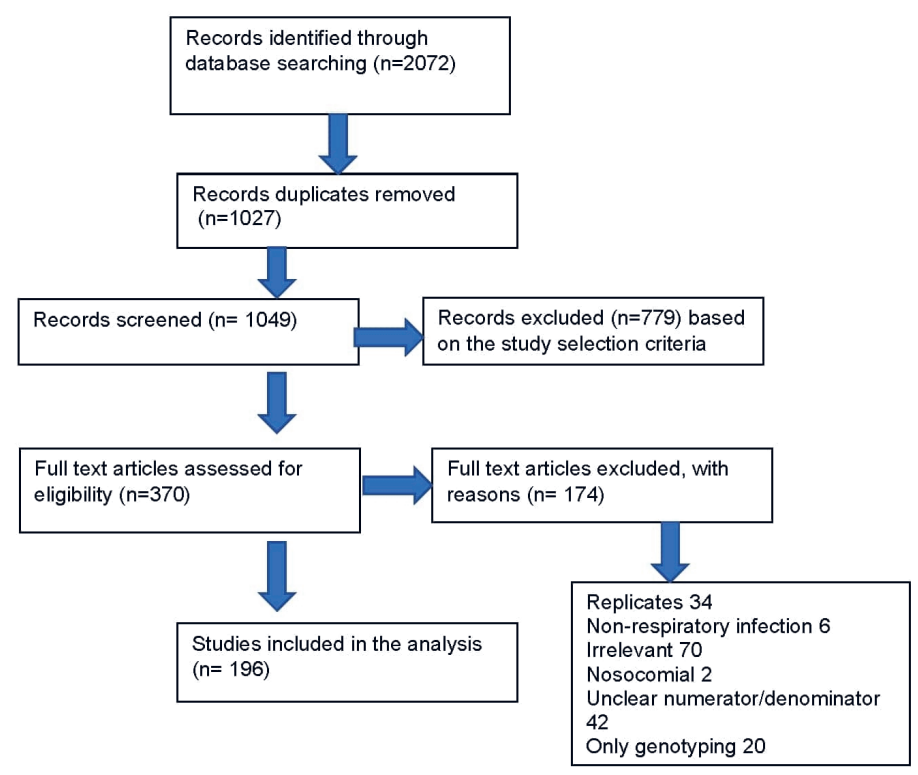

Figure 1. Flow diagram of studies selection. The criteria for identification of irrelevant studies adapted from previous publication [17] (1) did not discuss respiratory tract infections or respiratory syncytial virus (RSV),

(2) RSV mentioned only as background to discussion.

\section{RSV positive rate}

A total of 193 studies reported on the percentage of respiratory samples taken from patients with ARTI, LRTI or ILI that were positive for RSV, giving an overall positivity rate of $16.73 \%$ (95\% confidence interval $(C I)=15.12 \%-18.4 \%$ ) (Table 1). From the 196 studies that were included, 140 studies were conducted in children, 18 studies in adults, 38 studies covered all ages. The classification of age group (children and adult) was based on the classification used by each article. Of these studies, we then divided the age population into two categories (adult and children) by further extracting the data from the all-ages population to allow comparison of the positivity rate between the two categories. Among 


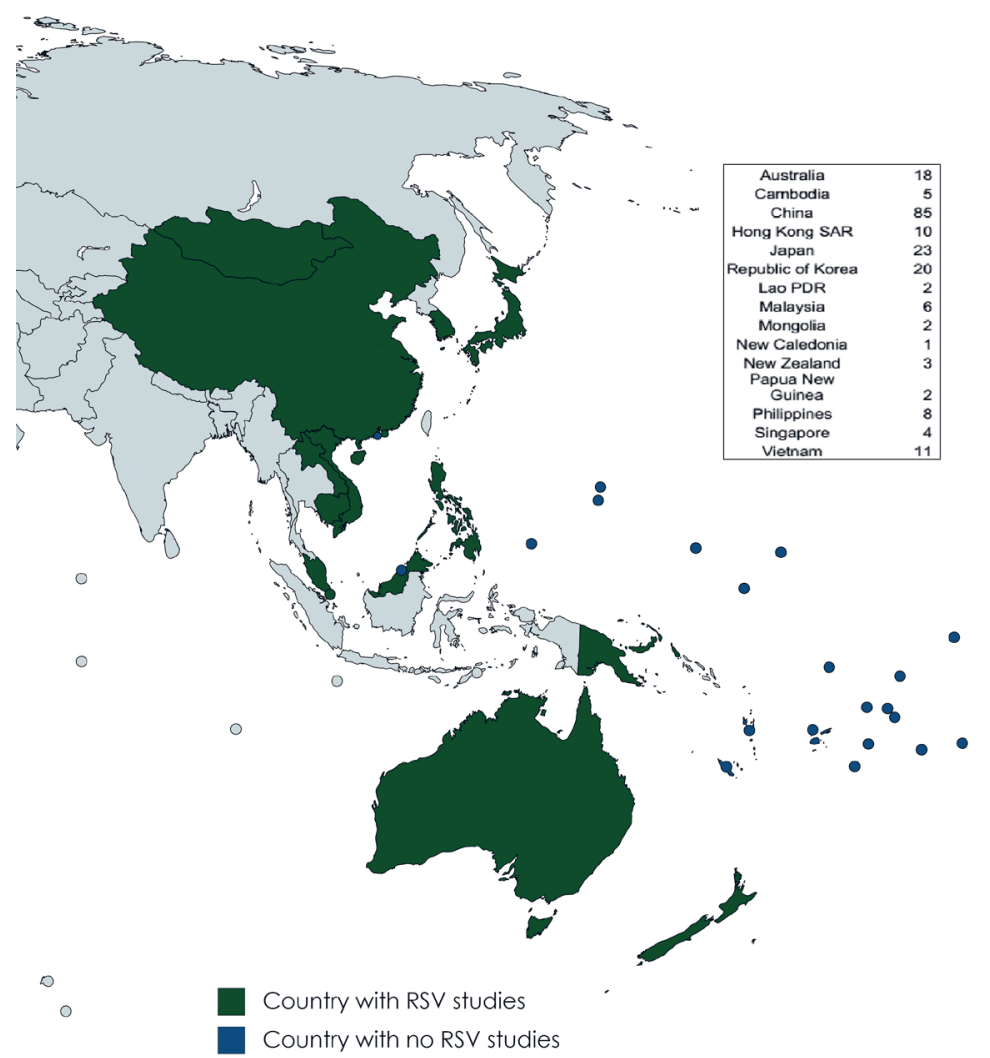

Created with mapehart.net $\odot$

Figure 2. Distribution of respiratory syncytial virus (RSV) studies in 15 of the 37 Western Pacific Region countries/areas. The WPR countries/areas are in green. Map was created with mapchart.net.

(Available from: http://mapchart.net).
868236 children, RSV was detected in 120137 (20.7\%, 95\% CI =18.68\%-22.83\%); and among 54915 adults, RSV was detected in 1003 (1.87\%, $95 \% \mathrm{CI}=1.37 \%-2.46 \%)$. The RSV positivity rate in children is significantly higher than in adults $\left(\chi^{2}=6535, P<0.001\right.$, Table 1$)$. Furthermore, the RSV positivity rate in children aged less than 5 years is higher than children older than 5 years (25.51\%, 95\% CI $=22.92 \%-28.19 \%$ vs $5.24 \%$, $95 \% \mathrm{CI}=3.36 \%-7.51 \%, P<0.001)$.

From the 193 studies that reported the prevalence of RSV based on the hospitalisation setting (inpatient, outpatient, or both), we classified the data into two categories, inpatients and outpatients, for analysis. There were 146 studies reporting RSV in hospitalised patients, 34 reporting RSV in outpatients, and 13 reporting RSV in both outpatients and inpatients. We also further extracted the data from these 13 articles to obtain each outpatients and inpatients data. RSV prevalence was higher in hospitalised inpatients (18.28\%, 95\% CI $=16.29 \%-20.4 \%$ ) than in outpatients $(11.89 \%, 95 \% \mathrm{CI}=9.22 \%-14.74 \%)$ $\left(\chi^{2}=180, P<0.001\right.$, Table 1$)$. In this study, RSV prevalence of hospitalised children is higher than in outpatient cases $(22.39 \%, 95 \% \mathrm{CI}=19.8 \%$ $25.1 \%$ vs $19.9 \%, 95 \% \mathrm{CI}=15.44 \%-24.77 \%$, $P<0.001$ ), while in outpatient adults, the positivity rate is higher than in hospitalised adults (3.11\%, 95\% CI $=1.36 \%-5.54 \%$ vs $1.43 \%, 95 \%$ $\mathrm{CI}=0.79 \%-2.26 \%, P<0.62)$.

\section{RSV incidence}

There were 15 studies reported the RSV incidence in eight countries/areas (Australia, China, Hong Kong SAR, Mongolia, New Zealand, Philippines, Singapore, Viet Nam), mostly in hospitalised children, while the outpatient incidence from ILI patients was reported in five countries (Table 2). The incidence of RSV-associated hospitalisation ranged between 4.9-30.9 per 1000 child-years and varied according to age group. There was only one study that provided the incidence of RSV-associated hospitalisation in adult patients, which was 0.57 per 1000 person-years [26]. The estimated incidence of RSV-associated ILI in children ranged from 0 to 137 per 1000 child-years [19,32].

\section{Seasonality}

One hundred and nineteen of the 196 studies reported the data related with the seasonality of RSV, including the duration, the week/month of the RSV season, and the peak of RSV activity (Table 3). Generally, temperate countries, both in the Northern and Southern hemispheres, experienced their peak of the epidemic in the winter. In subtropical and tropical countries, the cases peaked mostly in the rainy (wet) season. Several studies from countries that have a wide latitude range, such as China and Australia, have reported different times for the peaks of RSV epidemics depending on the latitude.

\section{RSV genotypes}

Forty-three studies reported the RSV subgrouping (RSV A and B). From the total 13775 RSV cases that underwent subgrouping, RSV A was identified in 8829 cases $(63.43 \%, 95 \% \mathrm{CI}=57.34 \%-69.31 \%)$ and RSV B in 4272 cases $(30.87 \%, 95 \% \mathrm{CI}=25.74 \%-36.25 \%$ ), respectively. There were 51 RSV cases from seven studies with concurrent RSV A and B infection.

The distribution of RSV genotypes between 1990-2015 was reported in 34 studies from eight WPR countries. Of these 34 studies, we used 33 studies that performed genotyping based on the G protein gene. 
Table 1. Respiratory syncytial virus (RSV) positivity rate based on the country, age, hospitalization status and virus methods

\begin{tabular}{|c|c|c|c|c|}
\hline & No. ARTICLES INCLUDED & TOTAL No. PATIENTS & No. RSV positive & \% RSV PositIVE (95\% CI) \\
\hline \multicolumn{5}{|l|}{ Country } \\
\hline Australia & 16 & 244370 & 33860 & $14.21(8.06-21.76)$ \\
\hline Cambodia & 5 & 11152 & 1002 & $8.80(4.13-14.9)$ \\
\hline China (excl. HK) & 85 & 508283 & 70495 & $15.69(13.7-17.78)$ \\
\hline Hong Kong SAR (China) & 10 & 143942 & 10193 & $9.55(3.4-18.35)$ \\
\hline Japan & 23 & 37690 & 6533 & $24.74(15.81-34.9)$ \\
\hline Malaysia & 6 & 76525 & 3686 & $15.76(4.45-32.24)$ \\
\hline Viet Nam & 11 & 12273 & 2135 & $15.97(8.68-24.96)$ \\
\hline Philippines & 8 & 33242 & 3336 & $20.23(8.17-35.97))$ \\
\hline New Zealand & 2 & 1601 & 681 & $50.13(29.19-71.04)$ \\
\hline Republic of Korea & 20 & 80633 & 6389 & $18.05(13.84-22.67)$ \\
\hline Mongolia & 2 & 542 & 52 & $13.03(2.36-30.4)$ \\
\hline Singapore & 4 & 52156 & 9196 & $13.58(9.64-18.06)$ \\
\hline Lao PDR & 2 & 675 & 199 & $26.72(5.88-55.6)$ \\
\hline Papua New Guinea & 2 & 380 & 44 & $14.74(3.99-30.65)$ \\
\hline New Caledonia* & 1 & 108 & 49 & $45.37(35.76-55.24)$ \\
\hline Total & $197 \dagger$ & 1203572 & 147850 & $16.73(15.12-18.4)$ \\
\hline \multicolumn{5}{|l|}{ Age group: } \\
\hline Children & $159 \dagger$ & 868236 & 120137 & $20.7(18.68-22.8)$ \\
\hline$<5 y$ & 48 & 184609 & 42206 & $25.51(22.92-28.19)$ \\
\hline$>5 \mathrm{y}$ & 16 & 11393 & 501 & $5.24(3.36-7.51)$ \\
\hline Adult & 34 & 54915 & 1003 & $1.87(1.37-2.46)$ \\
\hline \multicolumn{5}{|l|}{ Hospitalisation: } \\
\hline Inpatient & $155 \ddagger$ & 968885 & 118937 & $18.28(16.3-20.3)$ \\
\hline Outpatient & $43 \ddagger$ & 159574 & 17702 & $11.54(8.97-14.37)$ \\
\hline \multicolumn{5}{|l|}{ Virus detection methods§: } \\
\hline PCR & $121 \dagger$ & 307184 & 40897 & $16.04(14.04-18.15)$ \\
\hline IF & 29 & 459315 & 42229 & $17.7(13.93-21.9)$ \\
\hline Other & 17 & 93985 & 21532 & $22.5(17.35-28.14)$ \\
\hline Culture Mix & 29 & 334925 & 42381 & $15.65(11.42-20.41)$ \\
\hline
\end{tabular}

RSV - respiratory syncytial virus, CI - confidence interval, y - year

*CI was not calculated.

$\dagger$ Two studies covered three countries.

¥One study covered three countries.

§Other-serology/Enzyme Immunoassay (EIA), Culture Mix- combination of culture and any methods, PCR - polymerase chain reaction, IF - immunofluorescence.

Eleven RSV A and RSV B genotypes were identified from 3957 RSV cases (2841 RSV A and 1116 RSV B). The distribution of each genotype is shown in Figure 3. NA1 and BA genotypes were the predominant genotypes reported for RSV A and B, respectively. Japan, China and Malaysia had the most complete data as they had performed multi-year molecular epidemiology studies (Table S2 in the Online Supplementary Document).

\section{DISCUSSION}

Recently, RSV has received more attention as one of the major viral respiratory pathogens that cause significant mortality and morbidity, especially in younger children [2]. Several groups have determined the global burden of RSV infection in children by conducting a series of systematic reviews. The first systematic review and meta-analysis of global RSV data covering 1995-2009 estimated that, in 2005, the incidence of RSV-associated ARTI in children aged less than 5 years was 22\%, resulting in 3\%-9\% of all deaths, most of which (90\%) occurred in low- to middle-income countries [8]. Further analysis, using more recent publications and data, estimated that 28\% of ARTI episodes were RSV-associated, causing $13 \%-22 \%$ of all ARTI mortality in children aged under 5 years in 2015 [1]. A meta-analysis of pneumonia-related data conducted by the Global Action Plan for Pneumonia and Diarrhoea (GAPPD) group found that RSV is the most common aetiology of pneumonia in children, estimating that it contributes $29 \%$ of all episodes [34]. However, a systematic review of the adult population has rarely been performed. 


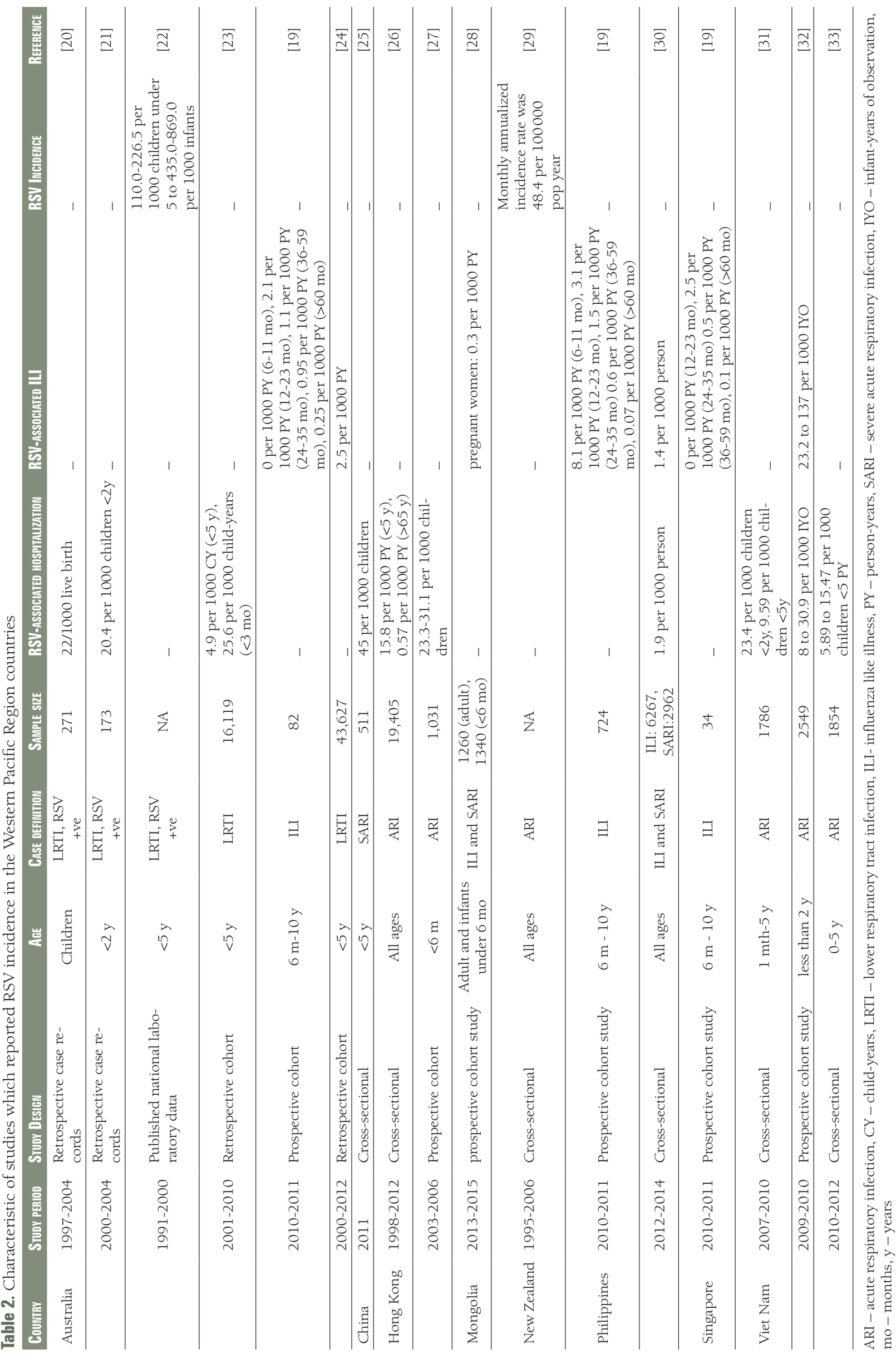


Table 3. RSV seasonality in the WPR countries

\begin{tabular}{|c|c|c|c|}
\hline & No ARticles INCLUDED & Seasonality & Peak or common months \\
\hline \multicolumn{4}{|l|}{ Southern hemisphere: } \\
\hline \multicolumn{4}{|l|}{ Australia } \\
\hline Temperate (NSW, Victoria) & 4 & Seasonal & Winter \\
\hline Subtropical (Queensland) & 1 & Seasonal & Winter \\
\hline Tropical (Queensland) & 1 & Seasonal & Rainy season \\
\hline Tropical (Northern Territory) & 1 & Throughout the year & Rainy season \\
\hline Desert (Northern Territory) & 2 & Throughout the year & Winter \\
\hline New Zealand & 1 & Seasonal & Winter \\
\hline \multicolumn{4}{|l|}{ Northern hemisphere: } \\
\hline \multicolumn{4}{|l|}{ China } \\
\hline Central & 2 & Seasonal & Winter and Spring \\
\hline \multirow[t]{4}{*}{ Eastern } & 7 & Seasonal & Winter \\
\hline & 7 & Seasonal & Winter and Spring \\
\hline & 1 & Seasonal & Autumn and Winter \\
\hline & 2 & Throughout the year & \\
\hline \multirow[t]{2}{*}{ Northeastern } & 4 & Seasonal & Winter \\
\hline & 1 & Seasonal & Winter and Spring \\
\hline Northwest & 5 & Seasonal & Winter and Spring \\
\hline \multirow[t]{5}{*}{ Southern } & 2 & Throughout the year & Winter and Spring \\
\hline & 4 & Throughout the year & Two peaks (winter to spring, summer to autumn) \\
\hline & 2 & Seasonal & Winter \\
\hline & 1 & Seasonal & Spring and summer \\
\hline & 2 & Seasonal & Spring \\
\hline Western & 2 & Seasonal & Winter \\
\hline \multirow[t]{2}{*}{ Japan } & 5 & Seasonal & Winter and Autumn \\
\hline & 3 & Seasonal & Winter \\
\hline \multirow[t]{3}{*}{ Republic of Korea } & 8 & Seasonal & Winter \\
\hline & 3 & Seasonal & Winter and Autumn \\
\hline & 2 & Seasonal & Winter and Spring \\
\hline Mongolia & 1 & Seasonal & Winter \\
\hline \multirow[t]{2}{*}{ Hong Kong } & 3 & Throughout the year & Rainy season \\
\hline & 3 & Two peaks & Winter-Spring, Summer-Autumn \\
\hline \multicolumn{4}{|l|}{ Tropical } \\
\hline Cambodia & 2 & Throughout the year & Rainy season \\
\hline \multirow[t]{2}{*}{ Viet Nam } & 5 & Throughout the year & Rainy season \\
\hline & 3 & Seasonal & Hot and dry season \\
\hline Lao PDR & 2 & Throughout the year & Rainy season \\
\hline Malaysia & 4 & Throughout the year & Rainy season \\
\hline New Caledonia & 1 & Seasonal & Transition from wet to dry season \\
\hline Philippines & 3 & Throughout the year & Rainy season \\
\hline Singapore & 2 & Throughout the year & Rainy season \\
\hline
\end{tabular}

RSV - respiratory syncytial virus, WPR - Western Pacific Region

In this review, the RSV pooled positivity rate is $16.73 \%$ of all acute respiratory infection cases in the WPR countries. The previous estimate based just on pneumonia episodes showed a higher RSV prevalence than our result [34]. Our result shows that the RSV-positive rate in both adult and child patients is higher than a previous systematic review of studies in Africa with a pooled prevalence of RSV infection in ARTI cases of $14.6 \%$ [10]. However, our RSV pooled prevalence is lower than the prevalence from systematic review studies in Latin America and Iran, where the RSV pooled prevalence was 18.7\% and 9.2\%-41.5\%, respectively $[9,35]$. The RSV positivity rate within the countries in the WPR ranged from $8.8 \%$ (Cambodia) to $50.13 \%$ (New Zealand). Our results show that the RSV prevalence in both adult and child patients in China of $15.6 \%$ (95\% CI $=13.7 \%-17.78 \%$ ) is similar to a previous systematic review where it was $18.7 \%$ (95\% CI $=17.1 \%-20.5 \%)[17]$.

The difference in RSV prevalence may be due to differences in the number of studies conducted within different countries, with most of the studies identified being from China, Japan, the Republic of Korea and Australia. These four countries have established strong national influenza surveillance programmes, 

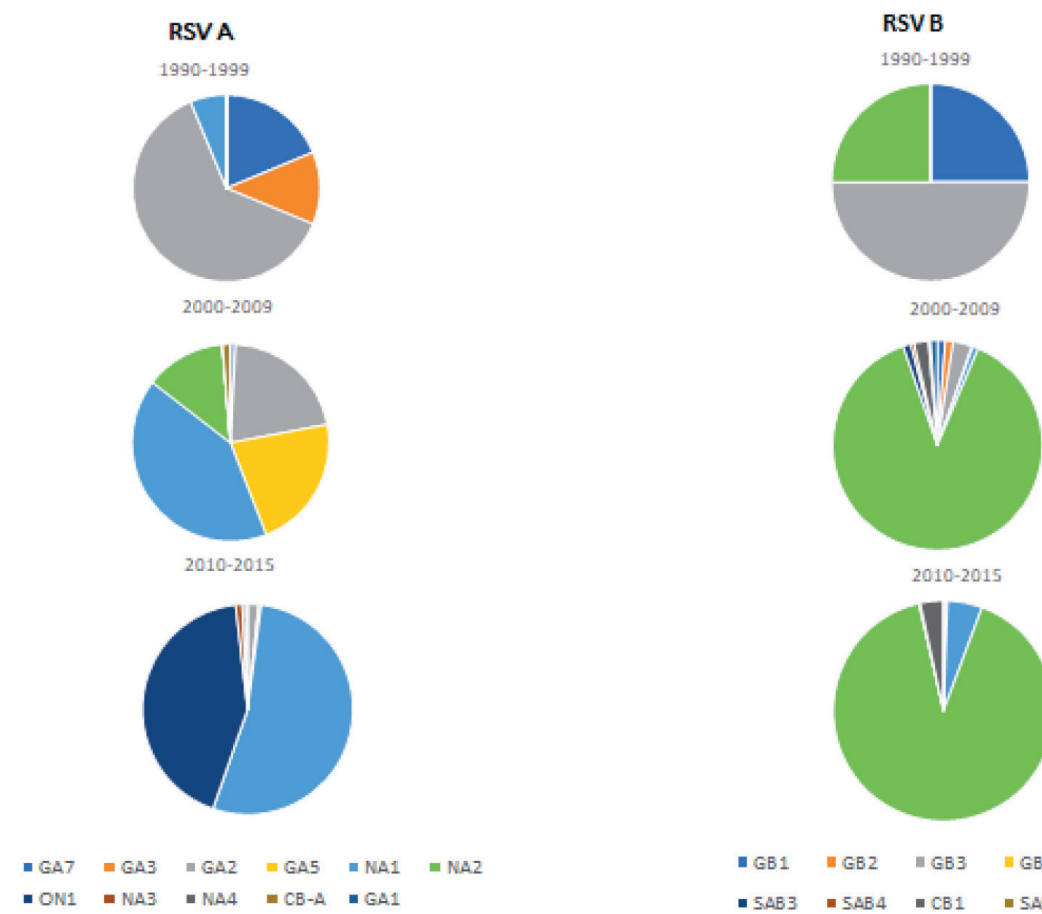

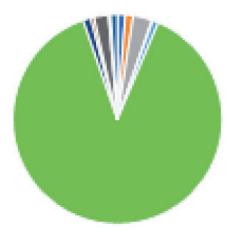

2010-2015

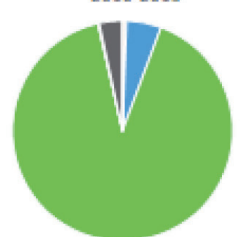

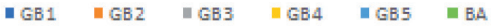

- SAB3 - 5AB4 - $\mathrm{CB} 1 \quad$-5AB2 $-\mathrm{CBB}$

Figure 3. Distribution of respiratory syncytial virus (RSV) genotypes in the Western Pacific Region countries.

which can be easily extended to cover other respiratory viruses [36]. Many of the studies in the WPR region were from the expansion of influenza-like illness (ILI) and severe acute respiratory infection (SARI) surveillance. Japan commenced RSV surveillance in 2003 [37], while the Korean Influenza and Respiratory Virus Surveillance System (KINRESS) for major respiratory viruses commenced in 2005, with sentinel sites located nationwide [38]. China has a nationwide influenza-surveillance system, but RSV surveillance is less well-established [36,39]. In Australia there is no national RSV surveillance system, however, there is monitoring of the trends of detected infections through several laboratories [22].

The RSV surveillance pilot project conducted by the WHO is based on the Global Influenza Surveillance and Response System and aims to provide evidence-based data, including on the epidemiology and circulation of RSV, that is needed for the implementation and monitoring of any future RSV vaccine [40]. This surveillance uses the existing influenza surveillance platforms that incorporate laboratory identification and molecular characterisation to monitor circulating genotypes and identify emerging viruses. This recent effort supports the Asia Pacific Strategy for Emerging Diseases (APSED), developed by WHO WPR and South East Asian Region (SEAR) member countries, that aims to guide member countries in achieving their obligations under the International Health Regulations (IHR 2005) [41]. Furthermore, the RSV surveillance pilot project may facilitate research on respiratory viruses as proposed by the BRaVE (Battle against Respiratory Viruses) initiative in 2013 [42].

The largest population group included in our RSV study is children with acute respiratory tract infections, 159 studies, which show a prevalence higher than the adult group. Our results are similar to previous systematic studies in both developing countries $[9,10]$ and developed countries $[43,44]$. The prevalence of RSV in adults is still not well-established compared with studies of adult influenza infection and the limited number of studies in adults might contribute to the lower reported prevalence in this age population. Based on our study, RSV has a considerable contribution to the WPR as an aetiology of respiratory infection, especially in children less than 5 years. Our analysis of the difference in the RSV positivity rate between children under 5 years and greater than 5 years is concordant with the results from African region [10]. As the specific prevention measure of an RSV vaccine is not yet available, other respiratory infection prevention and control measures targeted at this age group should be implemented in both developed and developing countries.

Most studies included in this review were conducted in hospital settings, with the percentage of RSV detected in inpatients being higher than in outpatients. Our results are similar to other studies where RSV 
prevalence was higher in hospitalised patients than in outpatients with ILI $[43,45]$. The RSV positivity rate in previous studies in hospitalised children varied between 3\%-29\% [46], which were similar to our result (22.38\%). However, our study found that the RSV positivity rate in outpatient adults was higher than in hospitalised adults, which is consistent with a study conducted in the United States demonstrating a higher rate of RSV emergency department visits than RSV hospitalisation rates in adults [47].

The reported incidence of acute respiratory infection in children due to RSV in the WPR countries is broad. The incidence of RSV-associated hospitalisation in children decreased with increasing age, a finding similar to previous studies [48-50]. A systematic review of children hospitalised due to RSV found that the incidence in the western countries (Australia, USA and Europe) was higher than in Asia [49], while in our study the incidence between western countries and Asia is similar. A study from Egypt reported a higher average annual incidence of RSV in outpatients than in hospitalised inpatients [51], while in the WPR countries only one study from Viet Nam showed similar results [32]. The variability of incidence has also been discussed in other studies possibly due to location, case definition, study population and diagnostic methods [49]. Our study provides additional data regarding the RSV burden in the outpatient setting to that in western countries [50]. As there are few studies of the acute respiratory RSV infection incidence in adults in the WPR, future research should focus on this age group.

The seasonality of infectious diseases, especially viral respiratory infections, is important for planning public health responses and workforce distribution, as seen for global influenza surveillance. Our results showed similar RSV seasonality that covered several locations that were not included in the previous review [52]. In the temperate regions in both the Northern and Southern hemispheres, RSV peaked in the winter season. In tropical countries, the seasonality of RSV is not clearly defined. However, the number of cases seems to peak at different times of the year, mostly in the rainy season. In Australia, the seasonality of RSV differs by region with the northern tropical part, including Cairns and Darwin, experiencing an RSV peak in the rainy season such as seen in neighbouring tropical countries [53].

Diagnostic methods for detecting respiratory viruses were advanced recently by the development of molecular methods for determining infectious aetiology. In this analysis, 121 studies used RSV polymerase chain reaction (PCR) assays to identify the respiratory viruses present during the acute respiratory infection. The positivity rate in the studies using PCR was similar to the studies using immunofluorescence (IF), which might be related to the specificity and sensitivity of the IF techniques [10]. A previous systematic review that included only studies using PCR had a higher RSV prevalence than studies using IF and immunochromatographic methods $[9,10,35]$. As we observed, there were reports of co-infection or co-detection of RSV with other respiratory viruses in the specimens tested, which were assumed to be due to the increased sensitivity of molecular methods [54-56].

Molecular methods have recently replaced monoclonal antibody determination of the grouping of RSV into RSV A and RSV B [57]. Recent studies analysed the distribution of RSV groups and genotypes and demonstrated that both RSV A and RSV B co-circulate in the same epidemic period with shifting predominance of the groups [58-61]. Further molecular characterisation studies identified various genotypes within each group, with each genotype able to cluster temporally, locally or circulate at different times and different global locations [58]. The molecular epidemiology studies conducted in the WHO WPR countries demonstrated the co-circulation of RSV A and RSV B with shifting dominance occurring between groups and changes to the diversity of the genotypes. RSV A was more dominant than RSV B in the WPR countries during the past two decades. This finding is concordant with studies conducted in other parts of the world [59-62].

Several studies in the WPR countries included sequencing to differentiate specific genotypes and examine their circulation, estimate pathways of transmission, and detect new and emerging genotypes. Japan, China, and Malaysia had relatively comprehensive molecular data over more extended periods. However, these molecular studies from large countries are often limited to a few sentinel sites and therefore may not be representative of the whole country's disease burden. RSV genotype circulation in the WPR countries followed a similar pattern to global circulation [63], as can be observed by the emergence of the new genotypes, BA (RSV B) and ON1 (RSV A). The RSV B BA genotype, first detected in specimens from Buenos Aires in 1999 [64], was first identified in the WPR from Malaysia's specimens in 1999 [65]. The BA genotype then further identified in several countries in the WPR region and became the dominant RSV B genotype. The distribution of RSV A ON1 genotype in the WPR countries also followed a similar pattern as in other global regions. The ON1 genotype was first identified in specimens from Ontario in 2010 [66] and emerged in 2011 in the WPR countries; in China [67], Malaysia [65] and Republic of Korea [68]. 
In the Southern hemisphere, the molecular epidemiology of RSV is not well-established as studies from Australia and New Zealand are limited. As an RSV vaccine is currently under development, data on the distribution of RSV strains will be important both for the composition of the vaccine and for post-vaccine implementation, particularly with regard to any immune selection pressure exerted by the vaccine.

Our study has some limitations. First, there were variations in the case definitions, study design, and pathogen detection methods used in these included studies. We had difficulty in classifying the children's age groups, as each countries' studies had differing age ranges. Therefore, the interpretation of the results has been cautious due to the difficulties in comparing some of these studies. In the future, it would be desirable to define the age-ranges of the children and adults when conducting epidemiology studies globally. Second, RSV is not the main focus of several studies, as most studies focused on finding other possible causes of respiratory infections. Third, the advances in PCR technology with increased sensitivity, which incorporate the detection of multiple respiratory viruses, allows for the inclusion of RSV, where it may not be the active infection. Therefore, as in the previous systematic review (10), we should consider the presence of viral co-infections in our future results. Lastly, the amount of data available per country is variable, with only half of the WPR countries having reported RSV and multiple studies from certain countries, which may bias the data, Despite this, our study has attempted to summarise data on the epidemiology of RSV in both adults and children in the WPR.

\section{CONCLUSION}

This study suggests that the RSV has considerable prevalence in the WPR countries, although the RSV data are limited as several countries have focused more on infections in children and hospitalised patients. The seasonality and the molecular epidemiology of RSV among WPR countries are similar to and reflect the global pattern. Further studies and surveillance incorporating molecular laboratory typing in adults and out-patients are needed to determine the overall burden of RSV infection in the WPR countries.

\footnotetext{
Funding: None

Authorship declaration: Study design (KP, AK, GAH); data collection (KP, MA); data analysis (KP, MA); data interpretation (KP,MA,AK, GAH); development of initial draft of manuscript (KP); critical revisions for intellectual content of manuscript (KP,MA,AK,GAH); study supervision (MA,AK,GAH). All authors reviewed and approved the final draft of manuscript.

Competing interest: All authors have completed the Unified Competing Interest form at www.icmje.org/coi_ disclosure.pdf (available on request from the corresponding author) and declare no conflicts interest.

\section{Additional material}

Online Supplementary Document
}

1 Shi T, McAllister DA, O’Brien KL, Simoes EAF, Madhi SA, Gessner BD, et al. Global, regional, and national disease burden estimates of acute lower respiratory infections due to respiratory syncytial virus in young children in 2015: a systematic review and modelling study. Lancet. 2017;390:946-58. Medline:28689664 doi:10.1016/S0140-6736(17)30938-8

2 Lozano R, Naghavi M, Foreman K, Lim S, Shibuya K, Aboyans V, et al. Global and regional mortality from 235 causes of death for 20 age groups in 1990 and 2010: a systematic analysis for the Global Burden of Disease Study 2010. Lancet. 2012;380:2095-128. Medline:23245604 doi:10.1016/S0140-6736(12)61728-0

3 Falsey AR, Cunningham CK, Barker WH, Kouides RW, Yuen JB, Menegus M, et al. Respiratory syncytial virus and influenza A infections in the hospitalized elderly. J Infect Dis. 1995;172:389-94. Medline:7622882 doi:10.1093/infdis/172.2.389

4 Malosh RE, Martin ET, Callear AP, Petrie JG, Lauring A, Lamerato L, et al. Respiratory syncytial virus hospitalization in middle-aged and older adults. J Clin Virol. 2017;96:37-43. Medline:28942341 doi:10.1016/j.jcv.2017.09.001

5 Binder W, Thorsen J, Borczuk P. RSV in adult ED patients: Do emergency providers consider RSV as an admission diagnosis? Am J Emerg Med. 2017;35:1162-5. Medline:28633906 doi:10.1016/j.ajem.2017.06.022

6 Pastula ST, Hackett J, Coalson J, Jiang X, Villafana T, Ambrose C, et al. Hospitalizations for Respiratory Syncytial Virus Among Adults in the United States, 1997-2012. Open Forum infect Dis. 2017;9:ofw270. Medline;28480262 doi:10.1093/ofid/ofw270 
7 Hall CB, Long CE, Schnabel KC. Respiratory syncytial virus infections in previously healthy working adults. Clin Infect Dis. 2001;33:792-6. Medline:11512084 doi:10.1086/322657

8 Nair H, Nokes DJ, Gessner BD, Dherani M, Madhi SA, Singleton RJ, et al. Global burden of acute lower respiratory infections due to respiratory syncytial virus in young children: a systematic review and meta-analysis. Lancet. 2010;375:1545-55. Medline:20399493 doi:10.1016/S0140-6736(10)60206-1

9 Bardach A, Rey-Ares L, Cafferata ML, Cormick G, Romano M, Ruvinsky S, et al. Systematic review and meta-analysis of respiratory syncytial virus infection epidemiology in Latin America. Rev Med Virol. 2014;24:76-89. Medline:24757727 doi:10.1002/rmv.1775

10 Kenmoe S, Bigna JJ, Well EA, Simo FBN, Penlap VB, Vabret A, et al. Prevalence of human respiratory syncytial virus infection in people with acute respiratory tract infections in Africa: A systematic review and meta-analysis. Influenza Other Respir Viruses. 2018;12:793-803. Medline:29908103 doi:10.1111/irv.12584

11 World Health Organization. Respiratory Syncytial Virus (RSV). Available: http://www.who.int/influenza/rsv/en. Accessed: 23 February 2018.

12 World Health Organization. WHO in the Western Pacific. Available: http://www.wpro.who.int/about/in_brief/en/. Accessed: 23 February 2018.

13 Rudan I, Boschi-Pinto C, Biloglav Z, Mulholland K, Campbell H. Epidemiology and etiology of childhood pneumonia. Bull World Health Organ. 2008;86:408-16. Medline:18545744 doi:10.2471/BLT.07.048769

14 Members of the WHO Western Pacific Region Global Influenza Surveillance and Response System. Epidemiological and virological characteristics of seasonal influenza in the Western Pacific Region of the World Health Organization, 20112015. Western Pac Surveill Response J. 2017;8:40-9. Medline:28409059 doi:10.5365/wpsar.2017.8.1.004

15 Moher D, Liberati A, Tetzlaff J, Altman DG. Preferred reporting items for systematic reviews and meta-analyses: the PRISMA statement. J Clin Epidemiol. 2009;62:1006-12. Medline:19631508 doi:10.1016/j.jclinepi.2009.06.005

16 DerSimonian R, Laird N. Meta-analysis in clinical trials. Control Clin Trials. 1986;7:177-88. Medline:3802833 doi:10.1016/0197-2456(86)90046-2

17 Zhang Y, Yuan L, Zhang Y, Zhang X, Zheng M, Kyaw MH. Burden of respiratory syncytial virus infections in China: Systematic review and meta-analysis. J Glob Health. 2015;5:020417. Medline:26682049 doi:10.7189/jogh.05.020417

18 Benet T, Sanchez Picot V, Messaoudi M, Chou M, Eap T, Wang J, et al. Microorganisms Associated with Pneumonia in Children $<5$ Years of Age in Developing and Emerging Countries: The GABRIEL Pneumonia Multicenter, Prospective, Case-Control Study. Clin Infect Dis. 2017;65:604-12. Medline:28605562 doi:10.1093/cid/cix378

19 Nolan T, Borja-Tabora C, Lopez P, Weckx L, Ulloa-Gutierrez R, Lazcano-Ponce E, et al. Prevalence and incidence of respiratory syncytial virus and other respiratory viral infections in children aged 6 months to 10 years with influenzalike illness enrolled in a randomized trial. Clin Infect Dis. 2015;60:e80-9. Medline:25673560 doi:10.1093/cid/civ065

20 Reeve CA, Whitehall JS, Buettner PG, Norton R, Reeve DM, Francis F. Predicting respiratory syncytial virus hospitalisation in Australian children. J Paediatr Child Health. 2006;42:248-52. Medline:16712553 doi:10.1111/j.14401754.2006.00849.x

21 Dede A, Isaacs D, Torzillo PJ, Wakerman J, Roseby R, Fahy R, et al. Respiratory syncytial virus infections in Central Australia. J Paediatr Child Health. 2010;46:35-9. Medline:19943864 doi:10.1111/j.1440-1754.2009.01614.x

22 Ranmuthugala G, Brown L, Lidbury BA. Respiratory syncytial virus-the unrecognised cause of health and economic burden among young children in Australia. Commun Dis Intell Q Rep. 2011;35:177-84. Medline:22010512

23 Homaira N, Oei JL, Mallitt KA, Abdel-Latif ME, Hilder L, Bajuk B, et al. High burden of RSV hospitalization in very young children: A data linkage study. Epidemiol Infect. 2016;144:1612-21. Medline:26626237 doi:10.1017/ S0950268815003015

24 Lim FJ, Blyth CC, Fathima P, de Klerk N, Moore HC. Record linkage study of the pathogen-specific burden of respiratory viruses in children. Influenza Other Respir Viruses. 2017;11:502-10. Medline:28991397 doi:10.1111/irv.12508

25 Huo X, Fang B, Liu L, Yu H, Chen H, Zheng J, et al. Clinical and epidemiologic characteristics of respiratory syncytial virus infection among children aged $<5$ years, Jingzhou city, China, 2011. J Infect Dis. 2013;208 SUPPL. 3:S184-8. Medline:24265477 doi:10.1093/infdis/jit518

26 Chan PKS, Tam WWS, Lee TC, Hon KL, Lee N, Chan MCW, et al. Hospitalization incidence, mortality, and seasonality of common respiratory viruses over a period of 15 years in a developed subtropical city. Medicine (Baltimore). 2015;94:e2024. Medline:26579810 doi:10.1097/MD.0000000000002024

27 Chiu SS, Chan KH, Chen H, Young BW, Lim W, Wong WH, et al. Virologically confirmed population-based burden of hospitalization caused by respiratory syncytial virus, adenovirus, and parainfluenza viruses in children in Hong Kong. Pediatr Infect Dis J. 2010;29:1088-92. Medline:20622713 doi:10.1097/INF.0b013e3181e9de24

28 Chaw L, Kamigaki T, Burmaa A, Urtnasan C, Od I, Nyamaa G, et al. Burden of Influenza and Respiratory Syncytial Virus Infection in Pregnant Women and Infants Under 6 Months in Mongolia: A Prospective Cohort Study. PLoS One. 2016;11:e0148421. Medline:26849042 doi:10.1371/journal.pone.0148421

29 Murdoch DR, Jennings LC. Association of respiratory virus activity and environmental factors with the incidence of invasive pneumococcal disease. J Infect. 2009;58:37-46. Medline:19042025 doi:10.1016/j.jinf.2008.10.011

30 Kamigaki T, Aldey PP, Mercado ES, Tan AG, Javier JB, Lupisan SP, et al. Estimates of influenza and respiratory syncytial virus incidences with fraction modeling approach in Baguio City, the Philippines, 2012-2014. Influenza Other Respir Viruses. 2017;11:311-8. Medline:28371393 doi:10.1111/irv.12453

31 Yoshida LM, Suzuki M, Nguyen HA, Le MN, Vu TD, Yoshino H, et al. Respiratory syncytial virus: Co-infection and paediatric lower respiratory tract infections. Eur Respir J. 2013;42:461-9. Medline:23645407 doi:10.1183/09031936.00101812 
32 Anders KL, Nguyen HL, Nguyen NM, Van Thuy NT, Hong Van NT, Hieu NT, et al. Epidemiology and virology of acute respiratory infections during the first year of life: A birth cohort study in Vietnam. Pediatr Infect Dis J. 2015;34:361-70. Medline:25674708 doi:10.1097/INF.0000000000000643

33 Yoshihara S, Kusuda S, Mochizuki H, Okada K, Nishima S, Simoes EAF. Effect of palivizumab prophylaxis on subsequent recurrent wheezing in preterm infants. Pediatrics. 2013;132:811-8. Medline:24127479 doi:10.1542/peds.2013-0982

34 Rudan I, O’Brien KL, Nair H, Liu L, Theodoratou E, Qazi S, et al. Epidemiology and etiology of childhood pneumonia in 2010: estimates of incidence, severe morbidity, mortality, underlying risk factors and causative pathogens for 192 countries. J Glob Health. 2013;3:010401. Medline:23826505

35 Salimi V, Tavakoli-Yaraki M, Yavarian J, Bont L, Mokhtari-Azad T. Prevalence of human respiratory syncytial virus circulating in Iran. J Infect Public Health. 2016;9:125-35. Medline:26143136 doi:10.1016/j.jiph.2015.05.005

36 Jennings L, Huang QS, Barr I, Lee PI, Kim WJ, Buchy P, et al. Literature review of the epidemiology of influenza B disease in 15 countries in the Asia-Pacific region. Influenza Other Respir Viruses. 2018;12:383-411. Medline:29127742 doi:10.1111/irv. 12522

37 Kanou K, Arima Y, Kinoshita H, Ito H, Okuno H, Saito N, et al. Respiratory Syncytial Virus Surveillance System in Japan: Assessment of Recent Trends, 2008-2015. Jpn J Infect Dis. 2018;71:250-5. Medline:29709974 doi:10.7883/ yoken.JJID.2017.261

38 Kim JM, Jung HD, Cheong HM, Lee A, Lee NJ, Chu H, et al. Nation-wide surveillance of human acute respiratory virus infections between 2013 and 2015 in Korea. J Med Virol. 2018;90:1177-83. Medline:29488229 doi:10.1002/jmv.25069

39 Yu J, Liu C, Xiao Y, Xiang Z, Zhou H, Chen L, et al. Respiratory Syncytial Virus Seasonality, Beijing, China, $2007-2015$. Emerg Infect Dis. 2019;25:1127-35. Medline:31107230 doi:10.3201/eid2506.180532

40 World Health Organization. WHO Technical Meeting on Piloting RSV Surveillance based on the Global Influenza Surveillance and Response System. Available: http://www.who.int/influenza/resources/publications/Technical_Meeting RSV_Pilot/en. Accessed February 23, 2018.

41 World Health Organization. Asia Pacific Strategy for Emerging Diseases. 2010. Available: http://www.wpro.who.int/ emerging_diseases/documents/docs/asped_2010.pdf. Accessed: 23 February 2018.

42 World Health Organization. Research need for the Battle against Respiratory Viruses (BRaVe). Available: http://www.who. int/influenza/patient_care/clinical/BRaVe_Research_Agenda_2013.pdf. Accessed: 23 February 2018.

43 Alimi Y, Lim WS, Lansbury L, Leonardi-Bee J, Nguyen-Van-Tam JS. Systematic review of respiratory viral pathogens identified in adults with community-acquired pneumonia in Europe. J Clin Virol. 2017;95:26-35. Medline:28837859 doi:10.1016/j.jcv.2017.07.019

44 Meerhoff TJ, Fleming D, Smith A, Mosnier A, van Gageldonk-Lafeber AB, Paget WJ. Surveillance recommendations based on an exploratory analysis of respiratory syncytial virus reports derived from the European Influenza Surveillance System. BMC Infect Dis. 2006;6:128. Medline:16899110 doi:10.1186/1471-2334-6-128

45 Druce J, Tran T, Kelly H, Kaye M, Chibo D, Kostecki R, et al. Laboratory diagnosis and surveillance of human respiratory viruses by PCR in Victoria, Australia, 2002-2003. J Med Virol. 2005;75:122-9. Medline:15543580 doi:10.1002/jmv.20246

46 Pavia AT. Viral infections of the lower respiratory tract: old viruses, new viruses, and the role of diagnosis. Clin Infect Dis. 2011;52 Suppl 4:S284-9. Medline:21460286 doi:10.1093/cid/cir043

47 Widmer K, Griffin MR, Zhu Y, Williams JV, Talbot HK. Respiratory syncytial virus- and human metapneumovirusassociated emergency department and hospital burden in adults. Influenza Other Respir Viruses. 2014;8:347-52. Medline:24512531 doi:10.1111/irv.12234

48 Emukule GO, Khagayi S, McMorrow ML, Ochola R, Otieno N, Widdowson MA, et al. The burden of influenza and RSV among inpatients and outpatients in rural western Kenya, 2009-2012. PLoS One. 2014;9:e105543. Medline:25133576 doi:10.1371/journal.pone.0105543

49 Stein RT, Bont LJ, Zar H, Polack FP, Park C, Claxton A, et al. Respiratory syncytial virus hospitalization and mortality: Systematic review and meta-analysis. Pediatr Pulmonol. 2017;52:556-69. Medline:27740723 doi:10.1002/ppul.23570

50 Bont L, Checchia PA, Fauroux B, Figueras-Aloy J, Manzoni P, Paes B, et al. Defining the Epidemiology and Burden of Severe Respiratory Syncytial Virus Infection Among Infants and Children in Western Countries. Infect Dis Ther. 2016;5:27198. Medline:27480325 doi:10.1007/s40121-016-0123-0

51 Rowlinson E, Dueger E, Taylor T, Mansour A, Van Beneden C, Abukela M, et al. Incidence and clinical features of respiratory syncytial virus infections in a population-based surveillance site in the Nile Delta Region. J Infect Dis. 2013;208 Suppl 3:S189-96. Medline:24265478 doi:10.1093/infdis/jit457

52 Bloom-Feshbach K, Alonso WJ, Charu V, Tamerius J, Simonsen L, Miller MA, et al. Latitudinal variations in seasonal activity of influenza and respiratory syncytial virus (RSV): a global comparative review. PLoS One. 2013;8:e54445. Medline:23457451 doi:10.1371/journal.pone.0054445

53 Hogan AB, Anderssen RS, Davis S, Moore HC, Lim FJ, Fathima P, et al. Time series analysis of RSV and bronchiolitis seasonality in temperate and tropical Western Australia. Epidemics. 2016;16:49-55. Medline:27294794 doi:10.1016/j. epidem.2016.05.001

54 Cilla G, Onate E, Perez-Yarza EG, Montes M, Vicente D, Perez-Trallero E. Viruses in community-acquired pneumonia in children aged less than 3 years old: High rate of viral coinfection. J Med Virol. 2008;80:1843-9. Medline:18712820 doi:10.1002/jmv.21271

55 Templeton KE, Scheltinga SA, van den Eeden WC, Graffelman AW, van den Broek PJ, Claas EC. Improved diagnosis of the etiology of community-acquired pneumonia with real-time polymerase chain reaction. Clin Infect Dis. 2005;41:34551. Medline:16007532 doi:10.1086/431588

56 Mahony JB. Detection of respiratory viruses by molecular methods. Clin Microbiol Rev. 2008;21:716-47. Medline:18854489 doi:10.1128/CMR.00037-07 
57 Sullender WM. Respiratory syncytial virus genetic and antigenic diversity. Clin Microbiol Rev. 2000;13:1-15. Medline:10627488 doi:10.1128/CMR.13.1.1

58 Cane PA. Molecular epidemiology of respiratory syncytial virus. Rev Med Virol. 2001;11:103-16. Medline:11262529 doi:10.1002/rmv.305

59 Peret TC, Hall CB, Hammond GW, Piedra PA, Storch GA, Sullender WM, et al. Circulation patterns of group A and B human respiratory syncytial virus genotypes in 5 communities in North America. J Infect Dis. 2000;181:1891-6. Medline:10837167 doi:10.1086/315508

60 Houspie L, Lemey P, Keyaerts E, Reijmen E, Vergote V, Vankeerberghen A, et al. Circulation of HRSV in Belgium: from multiple genotype circulation to prolonged circulation of predominant genotypes. PLoS One. 2013;8:e60416. Medline:23577109 doi:10.1371/journal.pone.0060416

61 Esposito S, Piralla A, Zampiero A, Bianchini S, Di Pietro G, Scala A, et al. Characteristics and their clinical relevance of respiratory syncytial virus types and genotypes circulating in northern Italy in five consecutive winter seasons. PLoS One. 2015;10:e0129369. Medline:26047100 doi:10.1371/journal.pone.0129369

62 Arbiza J, Delfraro A, Frabasile S. Molecular epidemiology of human respiratory syncytial virus in Uruguay: 1985-2001a review. Mem Inst Oswaldo Cruz. 2005;100:221-30. Medline:16113858 doi:10.1590/S0074-02762005000300001

63 Pangesti KNA, Abd El Ghany M, Walsh MG, Kesson AM, Hill-Cawthorne GA. Molecular epidemiology of respiratory syncytial virus. Rev Med Virol. 2018;•••:28. Medline:29377415 doi: 10.1002/rmv.1968

64 Trento A, Galiano M, Videla C, Carballal G, Garcia-Barreno B, Melero JA, et al. Major changes in the G protein of human respiratory syncytial virus isolates introduced by a duplication of 60 nucleotides. J Gen Virol. 2003;84:3115-20. Medline:14573817 doi:10.1099/vir.0.19357-0

65 Khor CS, Sam IC, Hooi PS, Chan YF. Displacement of predominant respiratory syncytial virus genotypes in Malaysia between 1989 and 2011. Infect Genet Evol. 2013;14:357-60. Medline:23305888 doi:10.1016/j.meegid.2012.12.017

66 Eshaghi A, Duvvuri VR, Lai R, Nadarajah JT, Li A, Patel SN, et al. Genetic variability of human respiratory syncytial virus A strains circulating in Ontario: a novel genotype with a 72 nucleotide G gene duplication. PLoS One. 2012;7:e32807. Medline:22470426 doi:10.1371/journal.pone.0032807

67 Cui G, Qian Y, Zhu R, Deng J, Zhao L, Sun Y, et al. Emerging human respiratory syncytial virus genotype ON1 found in infants with pneumonia in Beijing, China. Emerg Microbes Infect. 2013;2:e22. Medline:26038462 doi:10.1038/ emi.2013.19

68 Kim YJ, Kim DW, Lee WJ, Yun MR, Lee HY, Lee HS, et al. Rapid replacement of human respiratory syncytial virus A with the ON1 genotype having 72 nucleotide duplication in G gene. Infect Genet Evol. 2014;26:103-12. Medline:24820343 doi:10.1016/j.meegid.2014.05.007 